\title{
CDISC SDTM Adverse Event Outcome Terminology
}

National Cancer Institute

\section{Source}

National Cancer Institute. CDISC SDTM Adverse Event Outcome Terminology. NCI

Thesaurus. Code C66768.

Terminology associated with the adverse event outcome codelist of the Clinical Data

Interchange Standards Consortium (CDISC) Study Data Tabulation Model (SDT M). 